Voix et Images

volXetimages

\title{
Index du volume XXXVII
}

Volume 38, numéro 1 (112), automne 2012

URI : https://id.erudit.org/iderudit/1013459ar

DOI : https://doi.org/10.7202/1013459ar

Aller au sommaire du numéro

Éditeur(s)

Université du Québec à Montréal

ISSN

0318-9201 (imprimé)

1705-933X (numérique)

Découvrir la revue

Citer ce document

(2012). Index du volume XXXVII. Voix et Images, 38(1), 177-178.

https://doi.org/10.7202/1013459ar d'utilisation que vous pouvez consulter en ligne.

https://apropos.erudit.org/fr/usagers/politique-dutilisation/ 


\section{INDEX DU VOLUMEXXXVII}

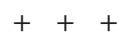

BIRON, Michel et Olivier

PARENTEAU, «La guerre dans la

littérature québécoise», 2, p. 9-14.

BLAIS, Marie-Claire, «Inédit. Le jeune homme sans avenir. Premières pages du sixième volet du cycle Soifs », 1, p. 27-30.

BOISCLAIR, Isabelle, «"D’hier à aujourd'hui, métamorphoses" », 1, p. $155-160$.

BONENFANT, Luc, «Car je est en prose. Ou le "traitement apporté au canon hiératique du vers" ", 3, p. 8596.

BRASSARD, Denise, «Oser la douleur», 1, p. 142-148.

BRASSARD, Denise, "Quand la pensée respire», 2, p. 144-151.

BRASSARD, Denise, " Noyer les lieux du livre. Lectures d'une filiation », 3, p. 35-54.

BRASSARD, Denise, "Corps mis à l'épreuve», 3, p. 172-178.
BROCHU, André, «L'inconscient ou non", 1, p. 149-154.

BROCHU, André, «Gaston et la gitane», 2, p. 152-157.

BROCHU, André, «D'Alain

Grandbois à Madeleine Gagnon en passant par Rina Lasnier», 3, p. 179184.

BROSSARD, Nicole, «Inédit», 3 , p. 31-34.

CAMBRON, Micheline, «Le discours sur la Grande Guerre. Demande d'histoire», 2, p. 15-33.

DION, Robert, «In gehender Bewegung", 2, p. 127-130.

GAGNON, Evelyne, «Circulation lyrique et persistance critique. Le passage au XxI ${ }^{e}$ siècle chez Nicole Brossard», 3, p. 69-83.

HAMEL, Yan, «La guerre pour la jeunesse», 2, p. 83-94.
HUGLO, Marie-Pascale,

«Émergences : mémoire et apparition dans Soifs », 1, p. 45-56.

INKEL, Stéphane, «Mémoire du présent. Double dette et forme d'une politique à venir dans le cycle Soifs ", 1, p. 87-98.

INKEL, Stéphane, «L'universel à l'épreuves des différences », 1 , p. 131-136.

INKEL, Stéphane, «Le Père, l'oubli», 3, p. 147-152.

JAROSZ, Krzysztof, « Métarécits », 2, p. 131-137.

JAROSZ, Krzysztof, «Lectures idiosyncrasiques», 3, p. 153-160.

KYLOUŠEK, Petr, «La poétique baroquisante de Marie-Claire Blais», 1, p. 57-71.

LAMONDE, Yvan, «Un visa chrétien pour l'art abstrait et pour un affranchissement. Marie-Alain Couturier, o.p. au Québec (19401945)», 2, p. 35-52. 
LAPOINTE, Martine-Emmanuelle, «Rencontres et solitude», 1, p. 137141.

LAPOINTE, Martine-Emmanuelle, «Et si l'Amérique n'existait pas», 3, p. 161-165.

LAROSE, Karim et Rosalie

LESSARD, « Nicole Brossard. Le genre premier», 3, p. 7-12.

LAROSE, Karim et Rosalie LESSARD, «Entretien avec Nicole Brossard», 3, p. 13-29.

LARRIVÉE, Stéphane et Andrée MERCIER, «De la voix autoritaire à la voix autorisée. Les tensions de la narration dans les Manuscrits de Pauline Archange», 1, p. 73-86.

LEBLANC, Julie, «Les carnets d'écriture inédits de Marie-Claire Blais. L'espace d'une œuvre en gestation», 1, p. 31-43.

LECLERC, Catherine et Lianne MOYES, «Littératures en contiguïté. France Daigle au Québec, France Daigle et le Québec», 3, p. 127-143.
MAILHOT, Valérie et Catherine PARENT BEAUREGARD,

"Bibliographie de Nicole Brossard", 3, p. 97-123.

NARDOUT-LAFARGE, Élisabeth,

«Le rendez-vous des fictions. Les

Canadiens errants et Rendez-vous à

l'Étoile», 2, p. 53-66.

PARENT, Marie, «Le corps accidenté chez Hélène Monette et Élise

Turcotte. L'Amérique des lieux clos", 1, p. 115-128.

PARENTEAU, Olivier, «La guerre chez les poètes de l'Hexagone. PaulMarie Lapointe, Fernand Ouellette et Jacques Brault», 2, p. 67-82.

RIENDEAU, Pascal, «Portraits

d'artistes », 2, p. 138-143.

RIENDEAU, Pascal, «Deux grands univers», 3, p. 166-171

ROBERT, Lucie, «"La force, qui trace les frontières, est-elle habile à disposer les peuples?" Guerre et histoire dans le théâtre d'André Ricard», 2, p. 95-107.
RONDEAU, Frédéric, «La résonnante. Échos de la mémoire chez Nicole Brossard», 3, p. 55-68.

ROY, Nathalie et Anne Élaine CLICHE, «Marie-Claire Blais : poétique de la voix», 1, p. 9-13.

ROY, Nathalie et Anne Élaine CLICHE, «Entretien avec MarieClaire Blais», 1, p. 15-25.

ROY, Nathalie, «Narration et traitement des personnages. Du visible à l'“espace derrière" dans le cycle Soifs », 1, p. 99-112.

\section{SAINT-MARTIN, Lori, «La}

rencontre des extrêmes », 2, p. 158161.

SUHONEN, Katri, «"Partout de la neige entassée, comme du linge à laver." La passion de la blancheur dans le roman québécois moderne», 2, p. 111-123. 